\title{
TOWARD THE INTRODUCTION OF TOURISM SATELLITE ACCOUNT-CASE STUDY GEORGIA
}

\section{GIORGI BREGADZE}

PhD, Professor

Caucasus University, Georgia

g.bregadze@iset.ge

Abstract. The paper stresses the importance of the introduction of the Tourism Satellite Account (TSA) in Georgia, describes the development stages of the system of tourism statistics for this purpose and identifies the recent weaknesses of the system. Furthermore, based on the recently created experimental TSA tables 1-4, the paper identifies the most affected tourism sectors by COVID-19 and estimates one of the main indicators of TSA - tourism direct gross domestic product in 2019 to equal $5,431 \mathrm{MM}$ Gel with a share in GDP of $12.6 \%$.

\section{KEYWORDS: SYSTEM OF TOURISM STATISTICS, EXPERIMENTAL TOURISM SATELLITE ACCOUNT, TOURISM DIRECT} GROSS DOMESTIC PRODUCT, COVID-19.

For citation: Bregadze, G., (2021). Toward The Introduction Of Tourism Satellite Account-Case Study Georgia. Globalization and Business, №11, 127-132. https://doi.org/10.35945/gb.2021.11.018

It is widely accepted among the public that tourism plays an essential role in the Georgian economy as the important contributor to the GDP and employment and one of the main sources of foreign exchange earnings. Although the last part of the sentence regarding the foreign exchange earnings can be validated through the existing data, the validation of the first part is still challenging. This challenge is caused by the definition of visitors, which differentiates them from other consumers "taking a trip outside his/her usual environment for less than a year and for a purpose other than employed by a resident entity there" (United Nations, 2010:10). Differently from output-defined industries such as agriculture, forestry, or manufacturing, the demand-defined tourism sector is not measured as an industry in its own right in national accounts. Output-defined industries are created based on their activity or output, rather than on data on their customers, while tourism is defined by the characteristics of the visitors (customers) at the moment of consumption. (OECD, Union, Nations, \& Organization, 2017:2). Furthermore, tourism consumption includes tourism-characteristic products (accommodation, travel services, recreation and entertainment events such as cultural festivals, etc.) and non-tourism-related goods and services (retail trade), which are delivered largely to non-tourists. The challenge from a measurement standpoint is to relate purchases by tourists to the total supply of these goods and services within a country. (OECD et al., 2017:24).

To deal with this challenge, the System of National Accounts 2008 suggests the use of satellite accounts, annexed to its core. A TSA makes it possible to separate and measure the demand and supply sides of tourism in an integrated system, which describes the production and demand aspects within the context of the entire economy. (OECD et al., 2017,:2) The TSA consists of ten tables, out of which the first six are regarded as core tables. The first four tables can be described as the demand side, while the fifth table is the supply side. The sixth table is called "the heart of the TSA", where reconciliation of demand and supply takes place. The seventh table compiles data concerning employment in the tourism industry. The eighth table collects data on the tourism gross fixed capital formation of tourism industries and other industries. The ninth table presents figures on tourism collective consumption by products and levels of government. The tenth and final concludes showing the non-monetary indicators. (Nations, 2010:534)

The primary goal of the paper is to estimate one of the main results of TSA: tourism direct gross domestic product. Furthermore, the paper describes the development stages of the system of tourism statistics in Georgia, identifies the recent weaknesses of the system, and identifies the most affected tourism sectors from COVID-19.

TSA measures the direct economic impacts of tourism and it is an account rather than the model (Douglas C. Frechtling, 2010:136), while for the estimation of the indirect and induced economic effects different types of economic models are utilized. The most frequently used models are input-output, Social Accounting Matrices and computable general equilibrium models. (Douglas C. Frechtling, 2013:18) Although there already have been attempts to build the input-output model with limited data for Georgia (Bregadze, 2018), for the author's best knowledge there is no existing study in Georgia of computable general equilibrium models incorporating tourism. 
Tourism Satellite account provides a framework for policy analysis by viewing tourism from multiple angles and can be beneficial for accomplishing multiple tasks. During peaceful times, the primary interest of policymakers is to understand all the channels through which tourism can contribute to the economy. Alternatively, in times of crisis, their interest changes toward estimation of a total loss to the economy, identification of most affected and vulnerable tourism fields to create relevant aid packages. TSA can play an important role during the COVID-19 pandemic and answer the fundamental question regarding the fair distribution of scarce financial aid between different stakeholders in the tourism industry. Policymakers choosing among different alternatives want to make sure that scarce financial aid is used by the sectors most in need.

The other papers concerning tourism and COVID-19 in Georgia concentrated on the policy actions necessary to mitigate the effect during the pandemic and restore tourism rapidly during the post-pandemic period (Erkomaishvili, 2020) overviewed the economic policy of tourism development in Georgia in the post-crisis period. The author stresses the importance of promotion of domestic tourism, regional tourism, organized tourism from several countries, as well as medical tourism. Furthermore, the author points out that special attention should be paid to the development of agricultural processing enterprises as the country is too dependent on imported goods (Beridze, 2020). It investigates the rural tourism development prospects after the COVID-19 pandemic in Georgia and mountainous regions of Adjara. Following the new trend of people avoiding crowded places, authors argue that this type of tourism will become popular among the visitors. Differently from these authors, this paper attempts to measure the actual effect of COVID-19 on tourism and based on the results identify most affected tourism activities. In general, TSA have the following benefits:

- Economic Impact. TSA allows measurement of the contribution of tourism in the economy, value-added generated to the economy, country revenues attributable to tourism, and contribution to employment. It also helps to understand how the market is evolving by providing consistent time series that reflect the composition of demand and supply;

- Structure of the Tourism Industry. TSA identifies the industries benefiting from tourism and their dependence level. The other way round it shows the composition of the sector, the industries providing goods and services to visitors, and their volume;

- Interconnection with other industries. It indicates the production function of tourism industries and illustrates interlinks between the tourism industries and the rest of the economy;

- $\quad$ Sources of Consumption. TSA locates the main goods and services purchased by the visitors and their importance to the total;

- Marketing. The government revenues attributable to tourism modules are linked to marketing return on investment estimates to calculate jobs supported and tax earned for tourism activities generated by marketing campaigns. Furthermore, it can determine break-even tax revenues to cover the investment in special marketing programs;
- Policy and Planning. It also provides input to the analysis of the strengths, weaknesses, opportunities, and strengths supporting better planning of tourism development and opens new avenues of public-private sector cooperation and developing non-traditional partnerships;

- Manpower, Education, and Training. The detailed information on the number of jobs can be used to make longterm labor supply/demand forecasts for occupations in the tourism industry to identify possible future labor, education, and training needs.

\section{System of Tourism Statistics of Georgia, history and recent developments}

The tourism Statistics System is a part of the National Statistics System and is a basic framework for coordinating and integrating statistical information on tourism. It incorporates concepts and definitions, classifications, and data sources, to describe tourism and provide internationally comparable measurements of its economic contribution. In this respect, its development is closely linked with TSA. (Affairs, 2017:5)

The system of tourism statistics went through a long way of different changes for the adaptation to the IRTS methodology involving in the process number of donors and experts. In 2012 GIZ within "The private sector development program" chose tourism statistics as the priority. At that point, Georgian National Tourism Administration was responsible for the compilation of tourism-related surveys, which were outsourced to the private company without a unified methodology. To address the challenges GIZ invited international as well as local experts. As a result, experts elaborated a strategy for improving the system of tourism statistics by prescribing specific functions of all the stakeholders. On top of the strategy, an action plan was proposed for establishing a temporary methodological group involving international and local experts (most importantly the representatives of GNTA, Geostat, and NBG) with the task to close all the open issues in the developed methodologies and agreeing on final guidelines. One of the actions was to gradually shift the responsibility of conducting surveys to Geostat.

Starting from 2014, based on UNWTO recommendations Geostat took over the responsibility of conducting inbound and domestic tourism surveys, for which a special sub-division was established. The same year Geostat started cooperation with Statistics Sweden, while in 2015 another expert group was invited again by Georgian National Tourism Administration with the help of GIZ to address the gaps in the methodology. The experts helped to solve several methodological issues, particularly:

The tourism concepts were redefined according to IRTS 2008 and the link established with the international visitor survey. The statistical information before 2017 was based on the arrival of foreign citizens. The number was further disintegrated into three categories, which were introduced by interior affairs without any relevance to tourism: 24 hours and more, transit, same day visit. The number of arrivals included all the people entering the country based on citizenship rather than residency and the usual environment concept was not defined. Furthermore, there was a clear inadequacy be- 
tween the number of travelers arriving in the country and the number of international visitors in the survey. Although the survey was conducted based on visitors departing from the country, the results were extrapolated on arrived visitors. To address the existed situation several concepts were redefined according to IRTS.

The number of questions in surveys was optimized, a methodology adapted and regularity defined. The survey was too large as it incorporated the interests of all possible stakeholders. A large number of questions harmed the quality of the results as several visitors refused to stay with the interviewer for a long time. The questions were analyzed by priority and only the most important one remained in the questionnaire. Furthermore, the methodology of domestic and outbound visitors was also created and regularity of data dissemination was set. A large number of scientific papers validated the use of surveys to estimate tourism expenditure. For example, seven most frequently used methods of estimation of tourism expenditures were compared by (D.C. Frechtling, 2006) concluding that if correctly applied, visitor surveys and cost factor models produce the most valid estimates.

Although demand-side issues have been largely solved with the help of experts the supply side remains still problematic. In general, there were some important developments on the supply side as well, but they did not solve the main obstacle for the compilation of TSA tables 5 and $6-$ the small sample size of the relevant surveys, which cannot serve good basis for the collection of comprehensive supply-side statistics to measure multiple dimensions of tourism at the 4-digit level of used classifications. The reforms on the supply side included the introduction of NACE 2 and SNA 2008 with several beneficial methodological changes:

- Update of intermediate consumption structure based on the special research;

- Identification of non-observed economy using the updated estimation methods in different sectors: Agriculture, Construction, Hotels, and Restaurants;

- Inclusion of output of non-legal activities in GDP;
- Inclusion of economic agents trading on fairs and market places in GDP

- Updated estimation methods of FISIM (Financial Intermediation Services Indirectly Measured);

- A revised method of measuring $\mathrm{OOH}$ (Owner-Occupied Housing) using the User Cost Method;

- Capitalization of costs concerning R\&D.

The difficulties with the compilation of TSA led to the introduction of fewer data demanding indicator for measuring share of tourism in GDP - Gross value added of tourism industries (GVATI), rather than Tourism direct gross domestic product (TDGDP), which is a more precise measure and one of the main results of TSA table 6 . The GVATI was introduced only on two-digit levels and equaled $8.3 \%$ in 2019. Recently the share of tourism in GDP is estimated based on this indicator.

Gross value added of tourism industries (GVATI) sums gross value added of all establishments related to tourism industries. This indicator has two shortcomings. First, it does not take into consideration whether the output is provided to visitors or locals. Second, it leaves out other non-tourism industries, whose output was acquired by visitors or by others on their behalf. On the other hand, tourism direct gross value added (TDGVA) calculates the part of gross value added generated by tourism industries and other industries of the economy directly serving visitors in response to internal tourism consumption. It also includes the part of gross value added associated with the output of other (non-tourism) industries as long as this output responds to tourism consumption. TDGVA plus the amount of net taxes on products and imports included within the value of this expenditure at purchasers' prices is TDGDP. (OECD et al., 2017:46) The concepts are summarized in the table below.

In 2019 Geostat started participation in the Twinning program "Strengthening the Capacity of the Georgian National Statistical System" to improve the statistical system of Georgia. Within the program, one of the tasks was to introduce experimental TSA tables 1 through 4. For this, changes were made in the surveys to include questions necessary for

Table 1: Comparison of methodological frameworks

\begin{tabular}{|l|l|}
\hline \multicolumn{1}{|c|}{ Indicators before 2017 } & \multicolumn{1}{|c|}{ Indicators after 2017 } \\
\hline $\begin{array}{l}\text { International Arrivals - the border crossing of foreign } \\
\text { citizens }\end{array}$ & $\begin{array}{l}\text { International traveler - someone who moves between different } \\
\text { geographic locations for any purpose and any duration. It excludes } \\
\text { foreign citizens who are Georgian residents and includes Georgian } \\
\text { citizens who are foreign residents. }\end{array}$ \\
\hline International Visitor-not defined & $\begin{array}{l}\text { International visitor is a traveler taking a trip to the main destination } \\
\text { outside his/her usual environment, for less than a year, for any purpose } \\
\text { (business, leisure, transit, or another personal purpose) other than to } \\
\text { be employed by a resident entity in the country or place visited. }\end{array}$ \\
\hline $\begin{array}{l}\text { 24 hours and more (tourists) - include visits that last more } \\
\text { than } 24 \text { hours. }\end{array}$ & $\begin{array}{l}\text { International visitor is classified as a tourist (or overnight visitor) if } \\
\text { his/her trip includes an overnight stay. }\end{array}$ \\
\hline $\begin{array}{l}\text { Transit Visits - include visits that last less than } \mathbf{2 4} \text { hours } \\
\text { in which the different border is used for entry and exit. }\end{array}$ & $\begin{array}{l}\text { Transit Visits are identified within the survey question - the main } \\
\text { purpose of visit }\end{array}$ \\
\hline $\begin{array}{l}\text { Same-day visits - include visits that last less than } \mathbf{2 4} \text { hours } \\
\text { in which the same border is used for entry and exit. }\end{array}$ & $\begin{array}{l}\text { A visitor (domestic, inbound, or outbound) is classified as a same-day } \\
\text { visitor (or excursionist) if his/her trip does not include an overnight } \\
\text { stay. }\end{array}$ \\
\hline Usual Environment - not defined & $\begin{array}{l}\text { To define the "usual environment" in Georgia, travelers conducting } \\
\text { eight or more trips per month are excluded from the data }\end{array}$ \\
\hline
\end{tabular}


Table 2: Macroeconomic Aggregates of Tourism

\begin{tabular}{|l|l|l|}
\hline $\begin{array}{l}\text { Gross value added of tourism } \\
\text { industries }\end{array}$ & Tourism direct gross value added & $\begin{array}{l}\text { Tourism direct gross domestic } \\
\text { product }\end{array}$ \\
\hline $\begin{array}{l}\text { Gross value added of all establishments } \\
\text { related to tourism industries regardless } \\
\text { of their production is provided to } \\
\text { visitors or non-visitors }\end{array}$ & $\begin{array}{l}\text { The part of gross value added generated by tourism } \\
\text { industries and other industries of the economy that } \\
\text { directly serve visitors in response to internal } \\
\text { tourism consumption }\end{array}$ & $\begin{array}{l}\text { TDGVA plus the amount of net } \\
\text { taxes on products and imports } \\
\text { included within the value of this } \\
\text { expenditure at purchasers' prices }\end{array}$ \\
\hline $\begin{array}{l}\text { Includes purchases of visitors and non- } \\
\text { visitors }\end{array}$ & $\begin{array}{l}\text { Includes purchases of visitors only } \\
\text { Includes purchases of visitors only }\end{array}$ \\
\hline
\end{tabular}

filling existing gaps. However, due to COVID-19, the international visitor survey is not conducted recently, as a result, the data compiled with the new methodology will not be available until the next year. Meanwhile, experts and members of the working group decided to estimate tables 1-4 based on the existing data. The author of the paper is a member of the working group within the EU Twinning program and this allows us to utilize estimated table 4 for the purposes of this paper.

\section{Experimental Tourism Satellite Account for Georgia}

The estimation of the size and importance of tourism for the Georgian economy is of paramount importance for the tourism policy formulation and TSA is the only validated method for this purpose. UNWTO recommends adopting an incremental staged approach to the development of a TSA, one element of which is the initiation of trial or "Experimental TSA". The term "experimental" in this context refers both to the tentative and provisional nature of the results as well as the experience of applying the recommended concepts, definitions, and procedures. In the initial "experimental" process usually following challenging limitations are identified: missing or limited data sources, ad hoc assumptions or facilitating estimation processes, relatively poor quality estimates of results, or irreconcilable aggregate results of derived output estimates in comparison with other key national aggregates used as comparative benchmark reference points (e.g., total output or GDP). In combination, such limitations preclude the acceptance of the Experimental TSA results as final and official at the initial stage of development. Instead, the results and the research and development process are described as "experimental" or "preliminary", and appropriate cautions are provided for their interpretation and application. The presented tables and figures below are experimental data resulting from the working group established by the Twinning program experts.

Table 4 represents total visitor expenditure in cash associated with inbound (TSA-table 1) and domestic tourism (TSA-table 2) consumption and "other components of tourism consumption" (in-kind). The result is called "internal tourism consumption".

The total value of internal tourism expenditure was $11,128 \mathrm{MM} \mathrm{Gel}$ in 2019, while the share of domestic visitor expenditure in total internal expenditure was $19 \%$. Accommodation services for visitors, Food and beverage serving services, Sports and recreational services represented the products that visitors demand the most with amounts of 2,104 $\mathrm{MM}, 1,804 \mathrm{MM}$, and 1,564 MM Gel respectively. This data has the following implications for COVID-19 tourism policy:

- The structure of internal tourism expenditure shows

Figure1: Internal tourism consumption by products 2019 (Million Gel)

$$
\begin{array}{ll}
\text { Inbound tourism } & \text { Domestic tourism } \\
\text { expenditure } & \text { expenditure }
\end{array}
$$

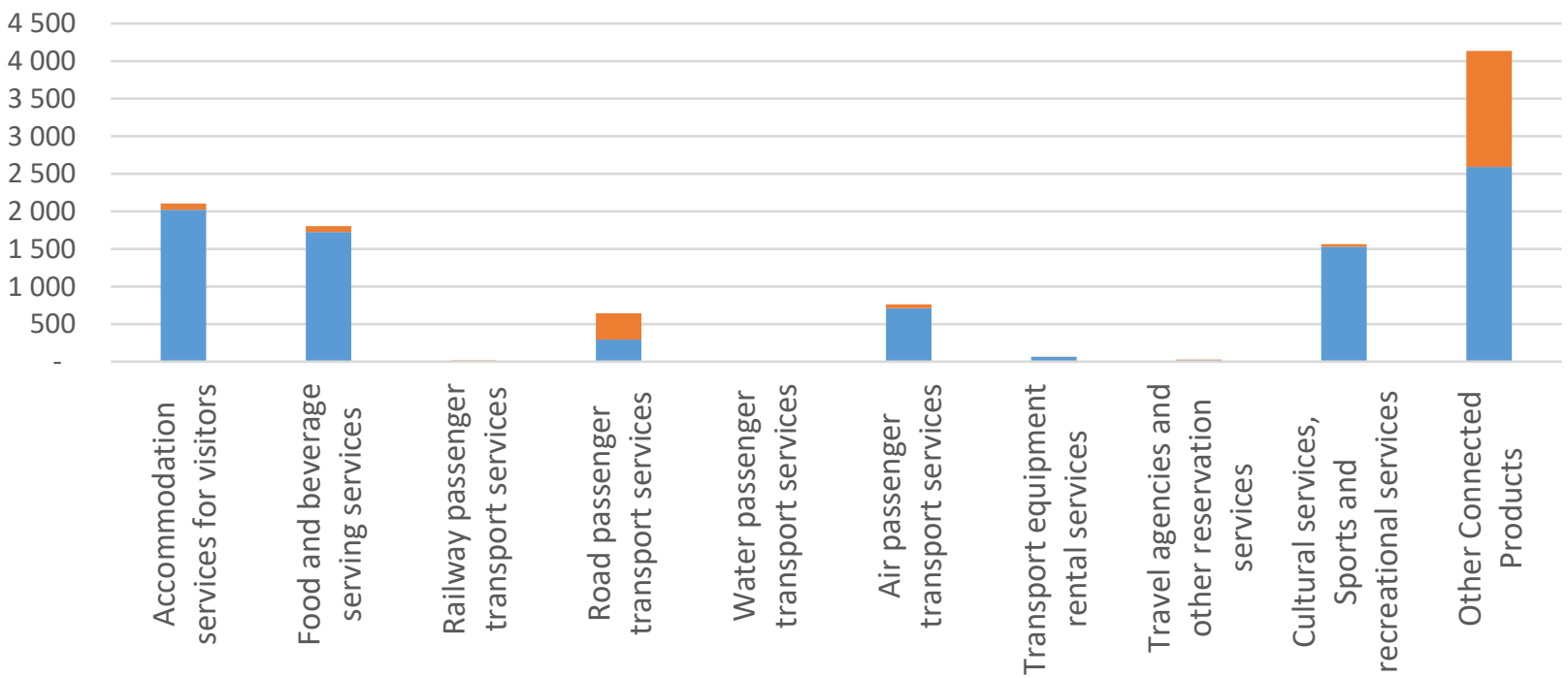


the total estimated direct effect of tourism and sectors benefiting from it. The most affected sectors from COVID-19 are those receiving the largest share of tourist expenditure. The data above shows the most affected categories: Accommodation Services, Food and Beverage Serving Services and Sports and recreational services;

- Another important indicator is the share of internal expenditure in the total supply of different sectors of the economy. It is important to recall that the expenditure of residents and non-residents generates total output. During the shocks, sectors primarily dependent on tourism are most affected. For example, category food and beverage incurred the largest loss in absolute terms, but residents would have compensated for the loss with their spending. TSA table 5 would be capable to show the share of tourism in each industry, identifying the major losers more precisely, but unfortunately recently table is not available in Georgia. Instead, the data from other countries and common sense can be used to locate tourism concentrated sectors, which are: Air Passenger Transport Services, Accommodation Services, and Travel agencies:

- The small share of domestic expenditure shows the high vulnerability of the country to external shocks. Domestic tourism cannot compensate for the decrease in foreign visitor expenditure. Road Passenger Transport Services showed the largest share of domestic tourism expenditure in internal expenditure equaling $37 \%$. Some policymakers argued that the restriction of outbound travel would complement international travel expenditure during the COVID-19 crisis, but recently published data on domestic tourism expenditure showed that was not the case.

Since the necessary data on the four-digit level to derive Tables 5 and 6 is not available in Georgia, UNWTO recommended paper "Proposals for estimating Tourism Direct GDP with limited data" will be employed to estimate the TDGDP. The paper describes an approach that might be used in the short term to compile estimates of TDGDP. The proposed approach is intended to provide a starting point for countries that can then move towards the compilation of TSA and the more complete measurement of TDGDP. This indicator should be regarded as experimental before the final measure would be available. The method implies the calculation of value-added ratios by dividing the gross value added of each tourism industry by its output. Then estimates of tourism direct gross value added (TDGVA) can be derived by multiplying the value-added ratio for each industry by the share of its output that has been purchased by visitors and summing across industries. For example, the total output of the category Accommodation was $2617 \mathrm{MM}$ Gel, while gross value added for the same category equaled $1071 \mathrm{MM}$ Gel in 2019, this gives a value-added ratio of $60 \%$. The received result is multiplied by the visitor expenditure on the same category $60 \% \times 2104$ MM Gel. GDP is derived by adding to TDGVA estimates of relevant taxes and subsidies on products applicable to visitor expenditure.

The estimated share of tourism in GDP is received by the ratio of the sum of the TDGDP 5,431 MM Gel and GDP at basic prices 43,138 equaling around $12.6 \%$ in 2019 . This number is significantly larger than Europe's average equaling $3.3 \%$. (Eurostat, 2019, p. 6) It should be mentioned that the value-added ratio was calculated using two-digit level indicators and the share of other connected products was estimated by taking the average of all value-added ratios of tourism products. Furthermore, the expectation is that the total output for each tourism characteristic product is higher than that visitor expenditure on that product. Unfortunately, this is not the case for our estimation for some products. This is caused by the fact that the demand side of the tables has not been calibrated with the supply side. Although there are some shortcomings with the estimation the received result has a significant meaning showing the importance of tourism for the Georgian Economy for the first time employing demand-side statistics.

\section{CONCLUSION}

The paper describes the introduction process of Tourism Satellite Account in Georgia as an effective tool for measuring the significance of tourism for the economy and policy analysis. The system of tourism statistics went through a long way of different changes for the adaptation to the IRTS methodology. As a result of multiple expert visits the system of tourism

Table 3: Experimental derivation of TDGDP

\begin{tabular}{|l|c|c|c|}
\hline \multicolumn{1}{|c|}{ Tourism Industries } & Value Added Ratio & $\begin{array}{l}\text { Internal Consumption } \\
(\text { MM) }\end{array}$ & TDGDP (MM) \\
\hline Accommodation services for visitors & $60 \%$ & 2,104 & 1,262 \\
\hline Food and beverage serving services & $40 \%$ & 1,804 & 721 \\
\hline Railway passenger transport services & $45 \%$ & 16 & 7 \\
\hline Road passenger transport services & $45 \%$ & 645 & 288 \\
\hline Water passenger transport services & $29 \%$ & 5 & 1 \\
\hline Air passenger transport services & $27 \%$ & 66 & 209 \\
\hline Transport equipment rental services & $44 \%$ & 28 & 29 \\
\hline Travel agencies and other reservation services & $41 \%$ & 1,564 & 11 \\
\hline $\begin{array}{l}\text { Cultural services, Sports and recreational } \\
\text { services }\end{array}$ & $56 \%$ & 4,135 & 876 \\
\hline Other connected Products & $49 \%$ & 11,128 & 2,026 \\
\hline Total & N/A & & 5,431 \\
\hline
\end{tabular}


statistics has been established and the roles assigned to each stakeholder. Furthermore, a methodological group involving main stakeholders was established and the responsibility to conduct surveys was assigned to Geostat. The concepts were redefined following IRTS 2008 recommendations and the number of questions in surveys was optimized. However, the significant problem on the supply side remains unsolved. The sample size of the relevant surveys is rather small and cannot serve good basis for the collection of comprehensive supply-side statistics to measure multiple dimensions of tourism at a 4-digit level of used classifications.

In this situation, the best solution is to conduct the Experimental Tourism Satellite account which allows an incremental staged approach and is not demanding toward the data indicators. The working group consisting of representatives of Geostat, GNTA, and Czech experts in the framework of the Twinning program estimated Experimental 1-4 tables.
Although the introduction of the first tables is important, without building the TSA table 6 where the most important indicator TDGDP is received, the conducted work is incomplete. To solve this shortness paper based on UNWTO recommended article "Proposals for estimating Tourism Direct GDP with limited data" estimates the TDGDP around $12.6 \%$. The estimation of the approximate indicator of the size of tourism in GDP from the demand side rather than supply (GVATI) has significant importance as for the first time the importance of tourism for the economy is stressed with the actual scientific data.

Finally, following the famous quote "If you can't measure it, you can't improve it" the paper stresses the need for the methodological changes on the supply side measurement of tourism and validation of the demand side to transform experimental tables into the final ones.

\section{REFERENCES}

Affairs, U. N. D. S. (2017). International Recommendations for Tourism Statistics 2008: Compilation Guide: United Nations Fund for Population Activities.

Beridze R., Kordzaia I., Diasamidze M, Beridze N. (2020). Sustainable Rural Tourism Development Recovery from Covid-19 (In Adjara Region). Globalization and Business, 10, 287-294. https://doi.org/10.35945/gb.2020.10.039

Bregadze, G., (2018). Priorities of Formation of Tourism Development Economic Policy: Tbilisi State University.

Erkomaishvili, G., (2020). Economic Policy for Tourism Development in Georgia in the Post-Coronavirus Period. Globalization and Business, 10: 257-260.

Eurostat. (2019). Tourism Satelite Accounts in Europe. Luxembourg: Publication Office in Luxembourg.

Frechtling, D. C., (2006). An Assessment of Visitor Expenditure Methods and Models. Journal of Travel Research, 45(41):26-35.

Frechtling, D. C., (2010). The Tourism Satelite Account: A Primer. Annals of Tourism Research, 37 (1):136-153. doi:https://doi. org/10.1016/j.annals.2009.08.003

Flechtling, D. C., (2013). The Economic Impact of Tourism: Overview and Examples of Macroeconomic Analysis. Madrid: UNWTO.

Nations, U. System of National Accounts 2008. doi:https://doi.org/10.18356/4fa11624-en

OECD, Union. E., Nations, U., \&Organization, W.T. (2017). Tourism Satelite Account:Recommended Methodological Framework 2008.

Obst, C., (2018) Measuring Sustainable Tourism: Proposals for Estimating Tourism direct GDP with Limited Data (Paper Presentation). 2018 Eighteen meeting - Committee on statistics and the Tourism Satellite Account, Madrid, Spain. https://www. unto.org/archive/global/event/eighteen-meeting-committee-statistics-and-tourism-satellite-account

United Nations., W. T. O. (2010). International Reccommendations for Tourism Statistics 2008: New York: United Nations. 